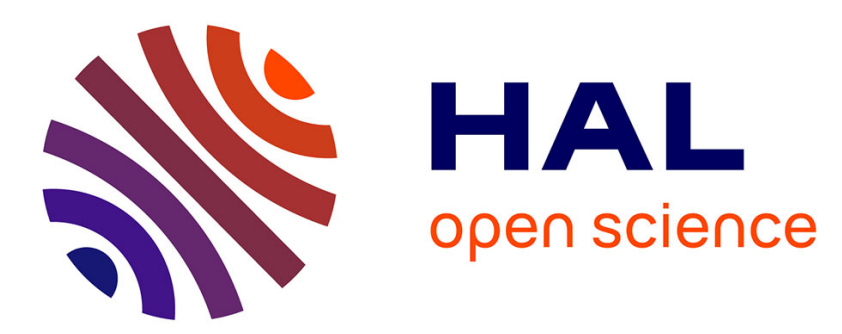

\title{
Polymer coil relaxation in uniaxially strained polystyrene observed by small angle neutron scattering
}

François Boué, M. Nierlich, G. Jannink, R. Ball

\section{To cite this version:}

François Boué, M. Nierlich, G. Jannink, R. Ball. Polymer coil relaxation in uniaxially strained polystyrene observed by small angle neutron scattering. Journal de Physique, 1982, 43 (1), pp.137-148. 10.1051/jphys:01982004301013700 . jpa-00209370

\section{HAL Id: jpa-00209370 https://hal.science/jpa-00209370}

Submitted on 1 Jan 1982

HAL is a multi-disciplinary open access archive for the deposit and dissemination of scientific research documents, whether they are published or not. The documents may come from teaching and research institutions in France or abroad, or from public or private research centers.
L'archive ouverte pluridisciplinaire HAL, est destinée au dépôt et à la diffusion de documents scientifiques de niveau recherche, publiés ou non, émanant des établissements d'enseignement et de recherche français ou étrangers, des laboratoires publics ou privés. 


\title{
Polymer coil relaxation in uniaxially strained polystyrene observed by small angle neutron scattering
}

\author{
F. Boué, M. Nierlich, G. Jannink and R. Ball \\ Laboratoire Léon-Brillouin, CEN Saclay, B.P. nº 2, 91191 Gif sur Yvette Cedex, France.
}

(Reçu le 23 juillet 1981, accepté le 11 septembre 1981)

\begin{abstract}
Résumé. - Le facteur de forme statique de chaînes linéaires de polystyrène amorphe $\left(M_{\mathrm{w}} \sim 650000\right)$ est mesuré par diffusion des neutrons aux petits angles après relaxation partielle de contrainte de l'échantillon soumis à une extension soudaine d'un facteur 3 maintenu constant. L'extension et la relaxation de contrainte sont effectuées à une température constante supérieure à $T_{\mathrm{g}}$. L'expérience a été faite à cinq températures différentes situées entre 113 et $134^{\circ} \mathrm{C}$. Les durées de relaxation se situent entre $10 \mathrm{~s}$ et $30 \mathrm{~min}$.

Aux temps les plus courts et aux températures les plus proches de $T_{\mathrm{g}}$, le rayon de giration transverse, qui est la plus grande longueur observable dans cette expérience, possède une valeur affine à la déformation macroscopique. Pour obtenir la variation de ce rayon sur une large gamme de temps, une superposition temps-température a été faite. Cette variation est comparée à la prédiction théorique de Doï et Edwards de contraction de la chaîne.

Dans le domaine de vecteur d'onde intermédiaire, les intensités diffusées dans la direction longitudinale pour différentes durées de relaxation suffisamment longues, peuvent être représentées par une fonction universelle d'un vecteur d'onde réduit $q / q^{*}$, où $\left(q^{*}\right)^{4}$ est proportionnel à la durée de relaxation. Ce comportement avait été prédit par Daoudi dans son étude du désengagement de la chaîne par reptation. Toutefois, le fondement théorique de cette étude devrait être discuté.
\end{abstract}

\begin{abstract}
Measurements are reported on the static form factor of the chains in a bulk amorphous unbranched polystyrene sample, $M_{\mathrm{w}} \sim 650000$, relaxing after an extensional step strain held constant at a factor 3 . The temperature of deformation and subsequent relaxation was above $T_{\mathrm{g}}$ and varied from $113{ }^{\circ} \mathrm{C}$ to $134^{\circ} \mathrm{C}$. Times of relaxation ranged from $10 \mathrm{~s}$ to $30 \mathrm{~min}$.

For the lowest temperatures and shortest times, the transverse radius of gyration, which is the largest characteristic length obtained from the neutron scattering data, showed a value affine with the macroscopic deformation. Timetemperature superposition is used to obtain the variation of the form factor over a wide range of reduced time. Its subsequent behaviour is compared with reptation theory predictions.

In the range of intermediate wavevectors, at high temperatures, the scattered intensities measured in the longitudinal direction for different times are consistent with a universal function of reduced wavevector $q / q^{*}$ where $\left(q^{*}\right)^{4}$ is proportional to the relaxation duration. This behaviour was predicted by Daoudi in a study of disengagement by reptation. Its interpretation should be rediscussed.
\end{abstract}

1. Introduction. - The observation of flexible chains in a melt during stress relaxation at constant strain helps us to understand how coils entangle and disentangle from each other. Present theories $[1,2,3]$ of such motions use the chain reptation model. The main experimental evidence for this comes from the non-linear stress relaxation in concentrated solutions [4] after a succession of step strains, and from the molecular weight dependence [5] of the coil diffusion coefficient in an unstrained melt. Here we present evidence from the observation of the static coil form factor measured by neutron scattering, at different times following a large step strain (by ratio 3). This technique allows the observation of the pair correla- tions over a large spatial range. We expect to obtain much more information than that derived for instance, from the birefringence stress optical coefficient [6]. Our experiment is the continuation of earlier work $[7,8]$ made however with improved sample preparation [9] and an enhanced signal to noise ratio [10].

The neutron scattering data are interpreted using a model in which the chain is confined to a tube made by the other chains. This model was first applied to describe the configuration of a coil trapped in a dry cross-linked gel [1]. In this case, the possibility of maintaining a constant deformation on the gel leads to the relaxation of the chain in a constant tube. The same derivation has been used for a chain in a 
polymer matrix of higher molecular weight $[1,3,11]$, the matrix relaxation being predicted slower by the cube of the mass ratio and so unimportant, giving a situation similar to that with the gel. Finally, the tube concept has been proposed to remain valid for a matrix of identical chains $[14,11,12,13]$, leading to a complete study [14] predicting the non-linear relaxation of stress and molecular configurations in the molten state.

In the following sections we will present

- the sample preparation (2),

- a discussion of the form factor (3),

- the experimental results (4),

and finally (in 5), we will present the time-temperature superposition, discuss the reptation predictions for the form factors both at low scattering vector (in terms of radii of gyration [14]) and higher scattering vector [3], give the orders of magnitude of their time scales, and compare our experimental results.

2. Sample preparation. - A blend of deuterated and hydrogenated polystyrene as shown in table I was mixed in a toluene solution and then vacuum cast. The dried bulk is annealed, vacuum molded at $185^{\circ} \mathrm{C}$ and reannealed [9] leading to a strip of length $L_{0}=8 \mathrm{~cm}$, width $2 \mathrm{~cm}$ and thickness 1 or $0.5 \mathrm{~mm}$. In order to provide a local macroscopic measure of the subsequent deformation, small equidistant lines are engraved perpendicular to the axial direction.

Each sample was then deformed and relaxed in an oven at a temperature $T$ greater than the glass temperature $T_{\mathrm{g}}$, maintained constant to within $\pm 0.5^{\circ} \mathrm{C}$ from one sample to another. The samples were first allowed to equilibrate to the oven temperature, then stretched [15] in pure extension at constant rate

$$
S=\frac{1}{L(t)} \cdot \frac{\mathrm{d} L(t)}{\mathrm{d} t}
$$

for a time $t_{\mathrm{S}}$ to reach a final length $L=\lambda L_{0}$. The effective extension was measured from the ratio of the distances between adjacent engraved lines before and after elongation; this ratio remained constant over a large region $(\sim 10 \mathrm{~cm})$ in the middle of the extended sample at a value within 0.1 of the overall extension $\lambda=3$. The deformation and the temperature were then held constant for a further time $t_{R}$ during which the internal state of the sample was allowed to relax. Finally the temperature was quenched to a value below $T_{\mathrm{g}}$ effectively freezing the coils in the then current state of the sample. Throughout all this time, the force exerted on the sample by the stretching machine was recorded. Quenching of the samples was simply achieved by opening the oven door : typically this "froze" the samples to below $T_{\mathrm{g}}$ within $10 \mathrm{~s}$.

Several samples were prepared with various values of oven temperature $T$ and times $t_{\mathrm{S}}$ and $t_{\mathrm{R}}$ in order to obtain samples in different states of relaxation, as shown in table II.

3. Measurement and features of the form factor. The Small Angle Neutron Scattering of the samples was measured at the ILL, Grenoble. The samples were cut and overlaid to provide a treble thickness $(1.2 \mathrm{~mm})$ then analysed on the D11 and D17 SANS spectrometers with neutron counting times of typically 3 hours and a $1 \mathrm{~cm}^{2}$ iris. The neutron detectors are both two dimensional and the wavevector of the incident beam was

$$
\left|\mathbf{k}_{0}\right|=\frac{2 \pi}{\lambda}= \begin{cases}0.63 \AA^{-1} & \mathrm{D} 11 \\ 0.48 \AA^{-1} & \mathrm{D} 17\end{cases}
$$

with a total dispersion of $\Delta k_{0} / k_{0}=10 \%$. Figure 1 shows the geometry of the experiment. The wavevector transfer $\mathbf{q}$ is related to the scattering angle $\theta$ by $|\mathbf{q}|=2 k_{0} \sin (\theta / 2)$ and its azimuthal angle $\varphi$ or orientation is here an important parameter (Fig. 1). In particular we will distinguish the two directions lying in the plane of the detector respectively parallel and perpendicular to the axis of stretching of the sample. The ranges of $q$ accessible and the coil dimensions are compared in table III.

3.1 USE OF HIGH CONCENTRATION OF DEUTERATED SPECIES. - A volume fraction of deuterated polysty-

Table I. - Molecular weight distributions of the two components of the samples polymer blend.

Hydrogenated polymer

Made and characterized

Mass characterization from G.P.C.

$$
\begin{gathered}
\bar{M}_{\mathrm{n}} \\
M_{\mathrm{w}} \\
M_{\mathrm{z}}
\end{gathered}
$$$$
\text { E.A.H.P., 4, rue Boussingault, }
$$$$
\text { Strasbourg Reference S572 }
$$

concentration $\left(\mathrm{g} / \mathrm{cm}^{3}\right)$
Deuterated polymer Made and characterized P. Rempp. laboratory, C.R.M. Strasbourg Reference SD2440

555000

784000

930000 
Table II. - Preparation characteristics of the sample, and obtained radii in perpendicular direction. The elongation ratio is $\lambda=3 \pm 0.1$.

\begin{tabular}{|c|c|c|c|c|c|}
\hline $\begin{array}{c}\text { Sample } \\
\text { number }\end{array}$ & $\begin{array}{c}\text { Rate of } \\
\text { stretching }\end{array}$ & $\begin{array}{c}\text { Duration of } \\
\text { stretching }\end{array}$ & $\begin{array}{c}\text { Duration of stress } \\
\text { relaxation }\end{array}$ & $\begin{array}{c}\text { Temperature } \\
\left({ }^{\circ} \mathrm{C}\right)\end{array}$ & $\begin{array}{c}\text { Perpendicular radius } \\
\text { of gyration }(\AA)\end{array}$ \\
\hline & & \multicolumn{2}{|c|}{ isotropic sample } & & $280 \pm 10$ \\
\hline 71 & $0.189 \mathrm{~s}^{-1}$ & $7 \mathrm{~s}$ & $30 \mathrm{~s}$ & 113 & \\
10 and 7 & $0.06 \mathrm{~s}^{-1}$ & $20 \mathrm{~s}$ & $10 \mathrm{~s}$ & 117 & $162 \pm 5$ \\
19 & $0.06 \mathrm{~s}^{-1}$ & $20 \mathrm{~s}$ & $20 \mathrm{~s}$ & 117 & $161 \pm 5$ \\
18 & $0.06 \mathrm{~s}^{-1}$ & $20 \mathrm{~s}$ & $1 \mathrm{~min}$. & 117 & $169 \pm 5$ \\
6 & $0.06 \mathrm{~s}^{-1}$ & $20 \mathrm{~s}$ & $4 \mathrm{~min}$. & 117 & $167 \pm 5$ \\
9 & $0.06 \mathrm{~s}^{-1}$ & $20 \mathrm{~s}$ & $20 \mathrm{~min}$. & 117 & $169 \pm 5$ \\
24 & $0.115 \mathrm{~s}^{-1}$ & $10 \mathrm{~s}$ & $10 \mathrm{~s}$ & 122 & $168 \pm 5$ \\
23 & $0.115 \mathrm{~s}^{-1}$ & $10 \mathrm{~s}$ & $1 \mathrm{~min}$. & 122 & $180 \pm 5$ \\
25 & $0.115 \mathrm{~s}^{-1}$ & $10 \mathrm{~s}$ & $20 \mathrm{~min}$. & 122 & $180 \pm 5$ \\
42 & $0.189 \mathrm{~s}^{-1}$ & $7 \mathrm{~s}$ & $30 \mathrm{~s}$ & 128 & $185 \pm 5$ \\
44 & $0.189 \mathrm{~s}^{-1}$ & $7 \mathrm{~s}$ & $1 \mathrm{~min}$. & 128 & $183 \pm 5$ \\
43 & $0.189 \mathrm{~s}^{-1}$ & $7 \mathrm{~s}$ & $8 \mathrm{~min}$. & 128 & $190 \pm 10$ \\
46 & $0.189 \mathrm{~s}^{-1}$ & $7 \mathrm{~s}$ & $30 \mathrm{~min}$. & 128 & $197 \pm 10$ \\
49 & $0.07 \mathrm{~s}^{-1}$ & $18 \mathrm{~s}$ & $1 \mathrm{~min}$. & 134 & $189 \pm 5$ \\
48 & $0.189 \mathrm{~s}^{-1}$ & $7 \mathrm{~s}$ & $1 \mathrm{~min}$. & 134 & $187 \pm 5$ \\
50 & $0.189 \mathrm{~s}^{-1}$ & $7 \mathrm{~s}$ & $16 \mathrm{~min}$. & 134 & $210 \pm 10$ \\
\hline
\end{tabular}

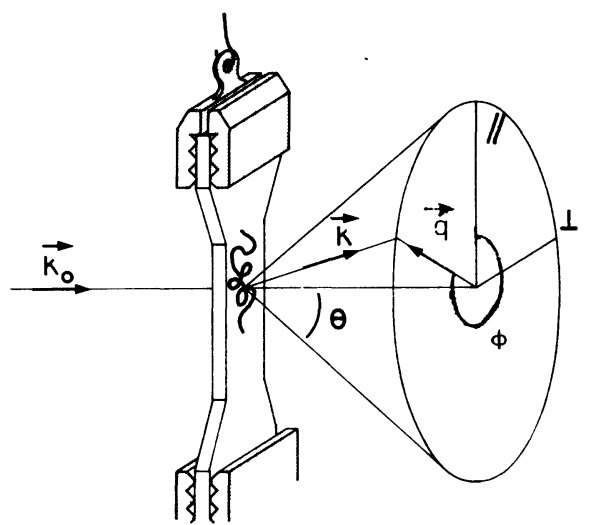

Fig. 1. - Schematic view of the small angle scattering set up. The incident neutron of wavevector $\mathbf{k}_{0}$, scattered by the sample, falls on the 2-dimensional detector. The wavevector transfer $\mathbf{q}$ lies in the detector plane. The characteristic directions $\perp$ and // are defined with respect to the sample elongation direction. rene $\varphi_{\mathrm{D}}=0.141$ was used in this experiment. Such a high concentration considerably increases the signal to noise ratio, while the coil interaction effect is still zero. This has been recently studied by several groups $[10,16]$ for melt blends of hydrogenated and deuterated chains of equal or different molecular weight distribution. In the former case, equality implies a symmetric relation

$$
I(q)=\varphi_{\mathrm{D}}\left(1-\varphi_{\mathrm{D}}\right) S(q) .
$$

This is valid not only in the isotropic state, but also in the deformed state, as we have previously verified [10] for any $\varphi$ between 0.03 and 0.7 . While the coherent scattering increases with $\phi_{\mathrm{D}}$ as $\varphi_{\mathrm{D}}(1-\varphi)$, the incoherent background decreases somewhat since, incoherently, deuterium scatters 40 times less than hydrogen.

Table III. - Scattering vector range for the two ILL spectrometers used here, compared to inverse radii in isotropic, or perpendicular and parallel affine value. All units in $\AA^{-1}$.

Inverse chain dimensions

$$
1 /\left(3 R_{\mathrm{giso}}\right)
$$

$$
1.19 \times 10^{-3}
$$$$
q_{\min } 5 \times 10^{-3}
$$$$
1 / R_{\mathrm{g} \text { iso }}
$$$$
3.6 \times 10^{-3}
$$$$
\sqrt{3} / R_{\mathrm{g} \text { iso }}
$$

D11 range

sample detector distance : $10 \mathrm{~m}$ wavelength : $10 \AA$

D17 range

sample detector distance $: 2.80 \mathrm{~m}$ wavelength : $13 \AA$

$$
q_{\min } 1.6 \times 10^{-2} \quad q_{\max } 6.2 \times 10^{-2}
$$


3.2 RADIUS OF GYRATION. - In the Guinier regime where $1 / q$ is large compared to the radius of gyration $R_{g}$, we can rigorously obtain the latter from the reduced slope of a plot of $1 / I(q)$ versus $q^{2}$ :

$$
\frac{R_{\mathrm{g}}^{2}}{3}=\frac{1 / I(q)-1 / I(0)}{q^{2} 1 / I(0)}
$$

For high molecular weights and hence large radii it is difficult to obtain sufficiently small $q$ to be absolutely certain of lying in the Guinier regime. However we are considerably aided by the slow departure of $1 / I(q)$ from its Guinier asymptote for an ideal gaussian chain. In Debye's calculation (see next paragraph), the Guinier asymptote intersects the high $q$ asymptote at $q R_{\mathrm{g}}=\sqrt{3}$, which gives a measure of how far out the Guinier law remains valid. For an isotropic sample on the D11 we are around this limit and the radius measured is :

$$
R_{\mathrm{g}}=280 \AA \text {, measured, within } \pm 10 \AA .
$$

This appears to be a good value, as it is much closer to the calculated radius [17].

$$
R_{\mathrm{g}}=0.275{\sqrt{M_{\mathrm{z}}}}=265 \AA \pm 10 \AA
$$

than to the apparent radius which would be obtained if equation (2) were mistakenly applied to the variation of $I(q)$ along the high $q$ asymptote, for which the calculated is :

$$
\sqrt{3} \times 0.275 \sqrt{M}_{\mathrm{n}}=355 \AA \pm 15 \AA .
$$

For stretched samples, as will be seen in part 4 , there is good evidence that the coils are affinely deformed for small $t_{\mathrm{R}}$. Thus in the perpendicular direction where all coil dimensions should be reduced by $\sqrt{\lambda}=1.732$ we are in a better position to observe the Guinier regime. However in the parallel direction where they should be increased by $\lambda=3$, there is no prospect of analysing $I(q)$ as a Guinier plot; even on the D11 spectrometer it is rather the intermediate regime (see below) which will be observed in the parallel direction.

3.3 INTERMEDIATE REGIME. - In the demain of large wavevectors, $q R_{\mathrm{g}} \gg 1$, the Debye calculation gives a straight line for $1 / I(q) \sim q^{2}$, with, compared to the Guinier line, half the asymptote and $3 / 2$ the slope. The wavevector must not, of course, reach inverse monomeric dimensions and there are corrections to these comparisons for polydispersity. Under affine deformation conditions, this regime should be observable on the D17 spectrometer, and in the parallel direction, even on the D11.

3.4 ANisotropy. - Using the whole plane of: $S(q)$ recorded by the two dimensional detector, we can plot in $\mathbf{q}$ space curves of equal scattered intensity. These iso-intensity curves join all the detector cells which have counted the same given number of neutrons. An isotropic sample must give circles, and affinely deformed samples should give ellipses with a // to $\perp$ axis ratio of

$$
\lambda^{3 / 2}=5.2 .
$$

4. Results. - 4.1 Stress data. - The recordings of the force for each sample were divided by its final cross-sectional area to give the stress $\sigma$, or more precisely the difference between the normal stresses in the $/ /$ and $\perp$ directions. Good agreement was obtained between curves of $\sigma\left(t_{\mathrm{R}}\right)$ as a function of time for different samples prepared at the same temperature, during both the stretching and the common relaxation periods. For each temperature $T$, the most complete $\sigma\left(t_{R}\right)$ curves were obtained from those'samples allowed to relax longest in the oven, and these data are presented as a log log plot in figure 5. The curves for the four different temperatures have been superposed as discussed in section 5 .

4.2 RAdi OF GYRation. - Figure 2 shows the plot of $1 / I(q)$ versus $q^{2}$ in the perpendicular direction in the D11 range (see Table III) for two samples; one quenched immediately after deformation at one of the lowest temperatures and the other isotropic. Straight lines with almost equal intercepts fit the experimental points well, and the scatter appears. satisfactory. The other samples have the same quality of data and show slopes increasing slowly with the time $t_{\mathrm{R}}$ and with the temperature. Table II shows the apparent radii of gyration obtained using equation (2).

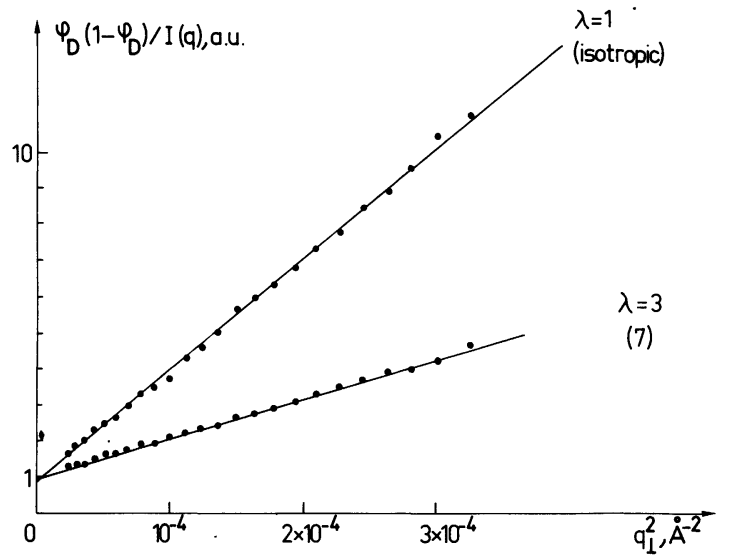

Fig. 2. - Inverse normalized scattered intensities in arbitrary units, versus the squared scattering vector in the transverse direction $\left(q_{\perp}^{2}\right)$, for the isotropic sample, and sample $n^{\circ} 7$ quenched just after stretching. The range of scattering vectors is here the upper edge of the Guinier range. The values at $q_{\perp}=0$ are identical and the ratio between the two slopes is equal to the affine ratio 3 .

4.3 ANISOTROPY. - An example of an iso-intensity curve as plotted by the ILL computer is given in figure 3. The data are those from the D11 detector for 


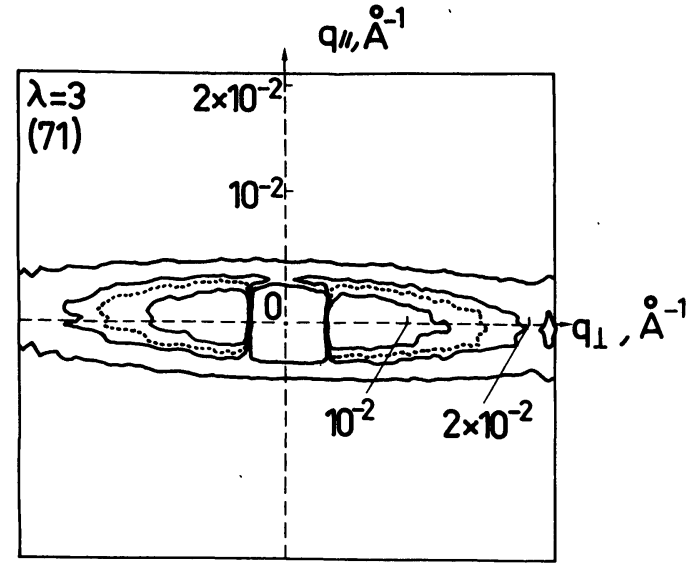

Fig. 3. - Curves of equal scattered intensities in the $q_{\perp} q_{\|}$plane for sample 71 quenched just after stretching. The ratio between the long and short axes of the curves is equal to the affine ratio $3^{3 / 2}=5.2$

the same stretched sample as in figure 1 . The curve is elliptical in shape with an axis ratio of $5.3 \pm 0.15$.

4. 4 Asymptotic Behaviour. - Figure 4 shows a plot of $1 / I(q) \sim q^{2}$ in the parallel direction on the D11 spectrometer, for an isotropic sample and two deformed samples relaxed at $128^{\circ} \mathrm{C}$. As $q$ increases the latter plots are curving below that for affine deformation, to an extent which increases with the time of relaxation. At much larger values of $q$ on the D17 spectrometer (see Table III), the slopes of the tangents of these plots approach the isotropic value.

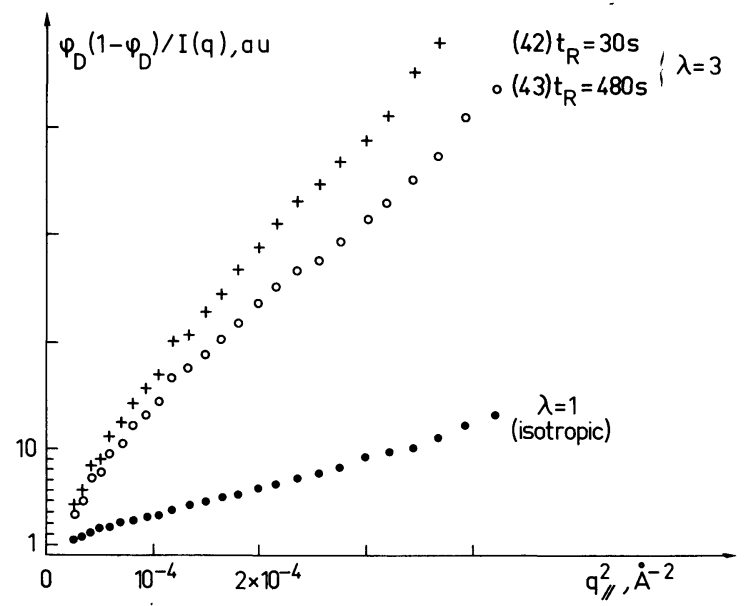

Fig. 4. - Reciprocal normalized scattered intensities in arbitrary units, versus the squared wavevector transfer in the longitudinal direction, at two different relaxation times $t_{\mathrm{R}}=30 \mathrm{~s}$, sample $42(+)$, and $t_{\mathrm{R}}=480 \mathrm{~s}$, sample 43 , (0). The range of wavevector transfer is here the intermediate range.

5. Discussion. - In this section we will discuss the validity of our sample preparation, the assumption of initially affine deformation, the influence of temperature, and finally the comparisons of $R_{\mathrm{g}}(t)$ with the predictions of Doï and Edwards and the intermediate range scattering with the calculation of Daoudi.

5.1 SAMPLE PREPARATION. - We have already remarked that for the same $T$ and $t_{\mathrm{S}}$ the stress history is reproducible, during stretching and during relaxation. Moreover, the form factors measured by neutron scattering for samples prepared in the same conditions are also found to be identical.

We want to approach the "sudden " deformation; we have in general used the shortest time of stretching $t_{\mathrm{S}}$ which does not cause breakage of the sample. Note that to keep $t_{\mathrm{S}}$ the same for all temperatures would be inappropriate since the relaxation times are different. If we stretch, at the same temperature, more slowly, the initial stress is lower, but beyond times of relaxation of the order of $t_{\mathrm{S}}$ the $\sigma(t)$ curves coincide again. We believe that the value of $t_{\mathrm{S}}$ has negligible influence for $t_{\mathrm{R}}>5 t_{\mathrm{S}}$ as is shown by the close agreement of $R_{\mathrm{g}}$ and $S(q)$ for the following samples

$$
\begin{array}{lll}
\mathrm{n}^{\circ} 48 & \left(t_{\mathrm{S}}=5.8 \mathrm{~s}\right. & \left.t_{\mathrm{R}}=1 \mathrm{~min} .\right) \\
\mathrm{n}^{\circ} 49 & \left(t_{\mathrm{S}}=16 \mathrm{~s}\right. & \left.t_{\mathrm{R}}=1 \mathrm{~min} .\right) .
\end{array}
$$

5.2 AfFINITY FOR SMALL $t_{\mathrm{R}}$. - To consider to what extent the initial state of the stretched sample is one of affine deformation, we measured the radii of gyration of the samples quenched immediately after stretching at low temperatures.

In the perpendicular direction, the measured Guinier slope gives a radius

$$
R_{\mathrm{g} \perp}=165 \pm 5 \AA
$$

identical to the affine value (see also Note added in proof)

$$
R_{\mathrm{g} \perp}=\frac{R_{\mathrm{giso}}}{\sqrt{\lambda}}=\frac{280 \pm 10}{\sqrt{3} \pm 0.1}=162 \pm 8 \AA .
$$

Also the iso-intensity curves (Fig. 3) give an axis ratio $5.3 \pm 0.15$ identical to the affine value

$$
\lambda^{3 / 2}=5.2 \pm 0.25 \text {. }
$$

For large times of relaxation (e.g. $16 \mathrm{~min}$. at $134^{\circ} \mathrm{C}$ ) the iso-intensity curves become much more circular.

5.3 SUPERPOSITION $t, T$. - In discussing the relaxation of $R_{\mathrm{g}}$ with time, we will use the time-temperature superposition principle [18]. This enables us to bring any data-stress, form factor-measured at $T$ and $t_{\mathrm{R}}$ back to a single reference temperature $T_{0}=117^{\circ} \mathrm{C}$ by assuming that these data correspond to data at $T_{0}$ at a rescaled time $\tilde{t}_{\mathrm{R}}$ simply proportional to $t_{\mathrm{R}}$ according to

$$
\tilde{t_{\mathrm{R}}}=t_{\mathrm{R}} \times \frac{a_{T}}{a_{T_{0}}} .
$$


We first applied this to stress measurements : figure 5 presents the plots of $\log \sigma$ versus $\log t_{\mathrm{R}}$ at each temperature, translated along the $\log t_{\mathrm{R}}$ axis in order to superpose the different curves. We thus found the following values for $\log _{10}\left(a_{T} / a_{T 0}\right): 0.85$ at $122{ }^{\circ} \mathrm{C} ; 1.54$ at $128{ }^{\circ} \mathrm{C} ; 2.15$ at $134{ }^{\circ} \mathrm{C}$. These values will be used to plot $R_{\mathrm{g} \perp}\left(\tilde{t_{\mathrm{R}}}\right)$.

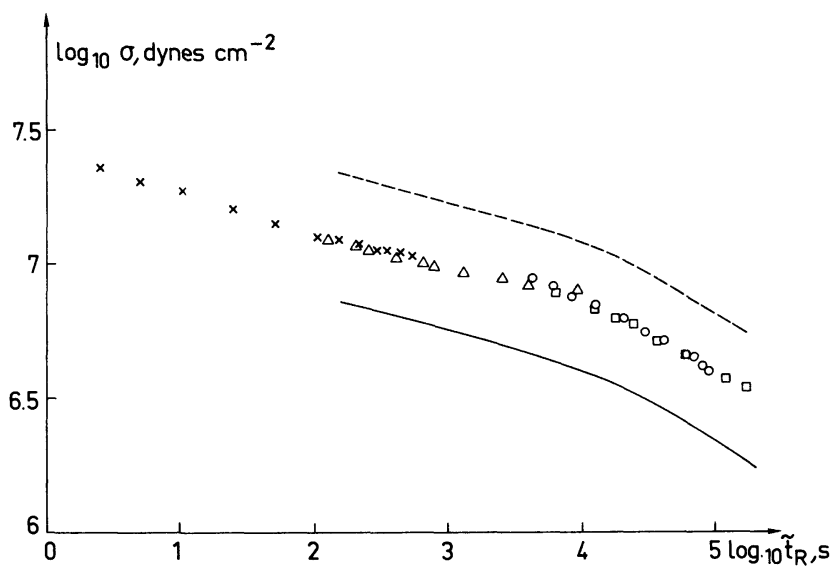

Fig. 5. - Representation of stresses measured at different relaxation times and temperatures, using the time temperature superposition principle :

$\times 117^{\circ} \mathrm{C} ; \Delta 122^{\circ} \mathrm{C} ; 0128^{\circ} \mathrm{C} ; \square 134^{\circ} \mathrm{C}$.

The temperature to which the relaxation times are reduced is $T=117^{\circ} \mathrm{C}$

The broken line represents the ideal rubber stress relaxation derived from the data of reference [20], with relaxation times reduced to the same molecular weight as in our sample, and to $T=117^{\circ} \mathrm{C}$. The continuous line is derived from the broken stress line using Doï Edwards contraction.

We can compare our values of $\log a_{T} / a_{T_{0}}$ to values in the literature, often given in the form $[18,27,20,28]$

$$
\log _{10} a_{T}=\frac{C_{1 \mathrm{~g}}\left(T-T_{\mathrm{g}}\right)}{C_{2 \mathrm{~g}}+T-T_{\mathrm{g}}} .
$$

For example Ferry [19] gives $C_{1 \mathrm{~g}}=13.7, C_{2 \mathrm{~g}}=50$ and Tobolsky [20] gives $C_{1 \mathrm{~g}}=17.44, C_{2 \mathrm{~g}}=51.6$, somewhat different. The translation values $\Delta \log _{10} a_{T}$ which we have used in 3 lie between the Ferry and Tobolsky values.

Finally we assume that this time-temperature effect applies to the temperature dependence of the theoretical predictions of Doï and Edwards [14] and Daoudi [3], since all the discussed times depend only on an elementary friction coefficient $\zeta_{0}(t)=\frac{a_{T_{0}}}{a_{T}} \zeta(T)$. Thus when extracting values of their characteristic times from literature data (see below) we will use this temperature dependence.

5.4 PREDICTIONS ON THE TIME DEPENDENCE OF THE RADIUS OF GYRATION. - We want to compare the experimental variation $R_{\mathrm{g} \perp}\left(\tilde{t}_{\mathrm{R}}\right)$ with the prediction of Doï and Edwards [14]. Their model assumes for a melt of identical chains, the existence of a tube surrounding each chain, with a characteristic length of the system, $a$, the tube diameter. They discuss the case of a sample kept at a constant final dimension after a sudden deformation, which can be large. From this, a particular behaviour of the return to equilibrium of the transverse radius has been derived by one of us [21]. It is assumed that the initial deformation is completely affine to the macroscopic one : this leads in a time $\tau_{10 c}$ (independent of $M_{\mathrm{w}}$ ) to immediate local reequilibration of the local linear density of chain segments along the tube, but because the chain will have suffered an average net curvilinear elongation, the uniform density so attained is not the equilibrium one. The existence of the tube will then induce two successive processes at two times which both lie in the range of time accessible by stress and neutron measurements (see next paragraph). First the linear density in each chain will return to equilibrium by a retraction of the chain inside its tube causing an isotropic shrinkage of the coil in a characteristic time $\tau_{\text {eq }} \propto M^{2}$. Note that even the transverse dimensions, deformed below their equilibrium value, should further decrease. Subsequently the chain will disengage itself from the tube, only by the ends, in a backward and forward reptation, forming a new isotropic tube, with a characteristic time $\tau_{\mathrm{dis}} \propto M^{3}$. The stress thus presents for $t>\tau_{\mathrm{loc}}$ two almost exponential decays which are clearly distinct if $\tau_{\text {dis }} / \tau_{\text {eq }}$ is sufficiently high, and the mass distribution narrow enough. The first decay $\tau_{\text {eq }}$ is a non-linear effect and has been clearly observed as a stress decrease in concentrated solutions by Osaki and Kurata [4].

The radius of gyration presents the same two times

$$
\begin{aligned}
& R_{\mathrm{g} \alpha}^{2}\left(t_{\mathrm{R}}\right)-R_{\mathrm{g} \text { iso }}^{2}=F\left(t_{\mathrm{R}} / \tau_{\mathrm{dis}}\right) \times \\
& \quad \times\left[R_{\mathrm{g} \alpha \text { aff }}^{2}\left(F\left(t_{\mathrm{R}} / \tau_{\mathrm{eq}}\right)\right)+\left(\frac{1-F\left(t_{\mathrm{R}} / \tau_{\mathrm{eq}}\right)}{\langle|\underline{\underline{E}} \cdot \underline{n}|\rangle}\right) \times R_{\mathrm{g} \text { iso }}^{2}\right]
\end{aligned}
$$

where $R_{\mathrm{g} \alpha}^{2}$ is the square radius of gyration in any particular direction $\alpha$ (as $/ /$ or $\perp$ ),

$R_{\mathrm{g} \alpha \text { aff }}^{2}$ is the affine value $\left(R_{\mathrm{g} \perp \text { aff }}^{2}=\frac{R_{\mathrm{g} \text { iso }}^{2}}{\lambda}\right)$,

$R_{\mathrm{g}}^{2}$ iso is the value at rest,

$F(x) \sim \mathrm{e}^{-x}$ within $1 \%$ for all $x$,

$\langle|\underline{E}: \underline{n}|\rangle$ is a bound on the retraction of the chain and is given in uniaxial extension by :

$$
\begin{aligned}
\langle|\underline{\underline{E}} . \underline{n}|\rangle & =\int_{0}^{\pi / 2} \sqrt{1 / \lambda \sin ^{2} \theta+\lambda^{2} \cos ^{2} \theta} \sin \theta \mathrm{d} \theta \\
& =1 / 2\left(\lambda+\frac{\sinh ^{-1} \sqrt{\lambda^{3}-1}}{\sqrt{\lambda} \sqrt{\lambda^{3}-1}}\right) \\
& =1.632 \text { for } \lambda=3 .
\end{aligned}
$$

Let us reiterate that before it is equilibrated completely by disengagement, the transverse radius should 
first retract even further from equilibrium over a time of order $\tau_{\mathrm{eq}}$. We thus have predicted a succession of relaxation phenomena clearly distinguishable in quality. We will now see that they must be well separated in time in order to observe them.

5.5 CHARACTERISTIC TIMES AND THEIR ORDERS OF MAGNITUDE. - In order to compare experiment and theory it is important to evaluate the characteristic relaxation times $\tau_{\text {eq }}$ and $\tau_{\mathrm{dis}}$. The discussion concerning this evaluation is given in the Appendix, and the results are as follows. The value of $\tau_{\text {eq }}$ derived from viscosity for our polystyrene sample at $T=117^{\circ} \mathrm{C}$ lies in the interval

$$
3 \times 10^{3} \mathrm{~s} \leqslant \tau_{\text {eq }} \leqslant 4 \times 10^{4} \mathrm{~s} .
$$

The value of $\tau_{\text {eq }}$ derived from the relaxation spectrum is

$$
\tau_{\mathrm{eq}} \sim 3 \times 10^{3} \mathrm{~s} .
$$

The value of $\tau_{\text {dis }}$ derived from stress relaxation and from the loss modulus lies in the interval

$$
6 \times 10^{5} \mathrm{~s} \leqslant \tau_{\mathrm{dis}} \leqslant 10^{7} \mathrm{~s} .
$$

The characteristic ratio, which will be found important in our experiment, is $\tau_{\text {dis }} / \tau_{\text {eq }}$ and its value derived from above lies in the interval

$$
25 \leqslant \tau_{\text {dis }} / \tau_{\text {eq }} \leqslant 2500 .
$$

This is to be compared to the ratio of the number $N$ of coil segments and $N_{\mathrm{e}}$ of segments between adjacent entanglements. The prediction is [22]

$$
\tau_{\text {dis }} / \tau_{\text {eq }}=6 N / N_{\mathrm{e}} \simeq 180 \text { (see Appendix). }
$$

5.6 OBSERVED STRESS RELAXATION. - We now discuss the stress data measurements in our experiment as a function of temperature. In figure 5 we compare the curve $\sigma\left(\tilde{t}_{\mathrm{R}}\right)$ to the Tobolsky data [20], obtained with $M_{\mathrm{w}} / M_{\mathrm{n}} \sim 1$. We have corrected the time for temperature and for mass with the factor $\frac{M_{\mathrm{n}} M_{\mathrm{n}-1} M_{\mathrm{n}-2}}{M_{\text {Tobolsky }}^{3}}$ for the onset of disengagement of the chain (see AIII in Appendix). To compare our large deformation stress data $\sigma(t)$ with the modulus $E_{\mathrm{r}}(t)$ reported by Tobolsky, we have shown the latter converted to a stress at $\lambda=3$ supposing two possible stress-strain relations. Firstly there is the ideal rubber value $\sigma=\frac{E_{\mathrm{r}}}{3}\langle\underline{\underline{E}} \cdot \underline{\underline{E}} \underline{\underline{E}} . \underline{n}\rangle=\frac{E_{\mathrm{r}}}{3}\left(\lambda^{2}-1 / \lambda\right)$ which lies well above our experimental curve; secondly we have plotted the fully retracted value of Doï and Edwards,

$$
\frac{E_{\mathrm{r}}}{3}(t)\left\langle\frac{\underline{\underline{E} \cdot \underline{n} \underline{\underline{E}} \cdot \underline{n}}}{|\underline{\underline{E} \cdot \underline{n} \mid}|}\right\rangle \frac{1}{\langle|\underline{\underline{E} \cdot \underline{n} \mid}|\rangle}
$$

LE JOURNAL DE PHYSIQUe - T. 43, No 1, JANVIER 1982 which lies well below. Thus we find the retraction correction somewhat too severe, in agreement with the much more precise shear measurements of Osaki [4]. Nevertheless the agreement in time is very satisfying within our experimental precision.

\subsection{OBSERVED TRANSVERSE RADIUS OF GYRATION. -} The transverse radii measured from the neutron scattering data are plotted in figure 6 in the form $\left(R_{\mathrm{g} \perp}^{2} / R_{\mathrm{g} \text { is }}^{2}\right)-1$ (see also Table II). On the same figure 6 , are also plotted two curves calculated from the predicted reduced time dependence of the same quantity (equation (5)) for two different pairs of times $\tau_{\text {eq }}, \tau_{\mathrm{dis}}$. We recall that introducing values for these latter is difficult because they both present an uncertainty of more than one decade, in such a way that

$$
4 \times 10^{-2}>\tau_{\text {eq }} / \tau_{\text {dis }}>4 \times 10^{-4} .
$$

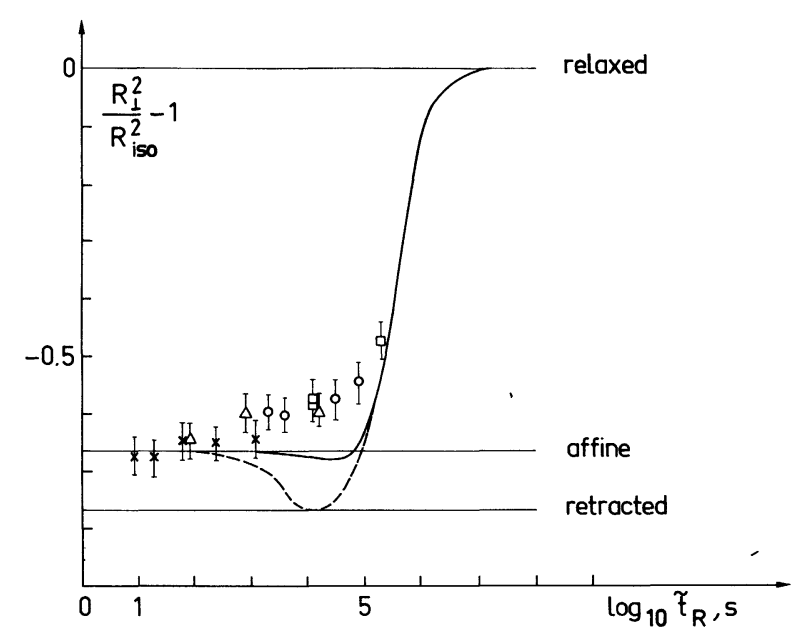

Fig. 6. - Representation of the reduced average square radius of gyration in the transverse direction, $R_{\perp}^{2} / R_{\mathrm{iso}}^{2}-1$, at different relaxation times and temperatures, using the time temperature superposition principle :

$\times 117^{\circ} \mathrm{C} ; \Delta 122^{\circ} \mathrm{C} ; 0128^{\circ} \mathrm{C} ; \square 134^{\circ} \mathrm{C}$.

The temperature to which the relaxation times are reduced is $T=117^{\circ} \mathrm{C}$

Calculated time dependences, from the affine deformed to the isotropic states, are given for a disengagement time $\tau_{\mathrm{dis}} \simeq 6 \times 10^{5} \mathrm{~s}$ and for equilibrium times $\tau_{\mathrm{eq}}=10^{-2} \tau_{\mathrm{dis}}$ (broken line),

$$
\tau_{\mathrm{eq}}=10^{-1} \tau_{\mathrm{dis}} \text { (continuous line). }
$$

We present two curves calculated for

$$
\tau_{\text {eq }} / \tau_{\text {dis }}=10^{-1}
$$

and

$$
\tau_{\text {eq }} / \tau_{\text {dis }}=10^{-2}
$$

and.we have calculated $\tau_{\text {dis }}$ for a monodisperse sample with a molecular weight $M$ related to the average of the molecular weight of our sample by 


$$
\tau_{\text {dis }}=\frac{\tau_{\mathrm{mTobolsky}}}{M_{\text {Tobolsky }}^{3}} \times M_{\mathrm{w}} M_{\mathrm{z}} M_{\mathrm{z}+1}=6 \times 10^{5} \mathrm{~s} .
$$

For the calculated curve with $\tau_{\text {eq }} / \tau_{\text {dis }}=10^{-1}$, we observe that the retraction is masked by the strong counter effect of disengagement but this is no longer the case for $\tau_{\mathrm{eq}} / \tau_{\mathrm{dis}}=10^{-2}$.

A second reason for smoothing the succession of processes will be polydispersity, which will increase the tendency of $R_{\mathrm{g} \perp}^{2}$ to show a monotonic relaxation.

If we now focus on the experimental data of figure 6 , we observe no retraction. We cannot be entirely confident that the physical effect is absent rather than masked by an insufficient ratio of $\tau_{\text {dis }} / \tau_{\text {eq }}$ and by polydispersity. We believe that a sample of molecular weight $M \sim 2 \times 10^{6}$ with $M_{\mathrm{w}} / M_{\mathrm{n}} \sim 1.05$ would suffice to put the issue beyond doubt.

5.8 ASYMPTOTIC BEHAVIOUR. - In the range $q R_{\mathrm{g}}>1$ the return of the form-factor $S(q)$ to its equilibrium value

$$
\frac{12}{q^{2} N_{\mathrm{n}} b^{2}+1}
$$

is observed, as the stress relaxes at constant strain. Figure 4 shows two steps towards equilibrium, which indicate that the latter is reached more quickly the larger the wavevector $q$. This fact is even more pronounced for samples 48 and 50 relaxing at $T=134{ }^{\circ} \mathrm{C}$.

A prediction was given by Daoudi for the spatial dependence of the relaxation rate of $S(q)$, for a free coil trapped in a suddenly deformed gel. We have used his result to interpret our data, although from a theoretical point of view its derivation and its application to polymer melts are both questionable. Surprisingly, we find however that it fits the data. The superposition principle proposed by Daoudi for the time dependence of the coil form factor, is written :

$$
\left.S_{\imath}(q)=\frac{2}{q^{* 2} R_{\mathrm{g} \text { iso }}^{2}} f_{\alpha}\left(q / q^{*}\right)\right\} \quad q R_{\mathrm{g}} \gg 1
$$

where $\alpha$ indexes the direction (e.g. $/ /$ or $\perp$ )

$$
q^{*}=\frac{\sqrt{3} \times \pi}{R_{\mathrm{g} \text { iso }}}\left(\frac{2 t}{\tau_{\mathrm{dis}}}\right)^{-1 / 4}
$$

where $t$ is the time after completion of the coil contraction. The length $q^{*-1}$ is isotropic and the function $f_{\alpha}(x)$ accounts for the change of behaviour between the affine deformation $(x<1)$ and the isotropic relaxed state $\lim _{x \rightarrow \infty} f_{\alpha}(x)=1 / x^{2}$.

We apply this principle assuming that the time $t$ can be identified with $t_{\mathrm{R}}$.

We compare the observed variation of the scattered intensities at time $\tilde{t}_{\mathrm{R}}, I_{\tilde{t}_{\mathrm{R}}}(q)$, to the formulation of the superposition principle.

Figure 7 shows an example of our procedure for samples 42 and 44 . Let $\tilde{t}_{\mathbf{R}_{42}}$ and $\tilde{t}_{\mathbf{R}_{44}}$ be the correspond-

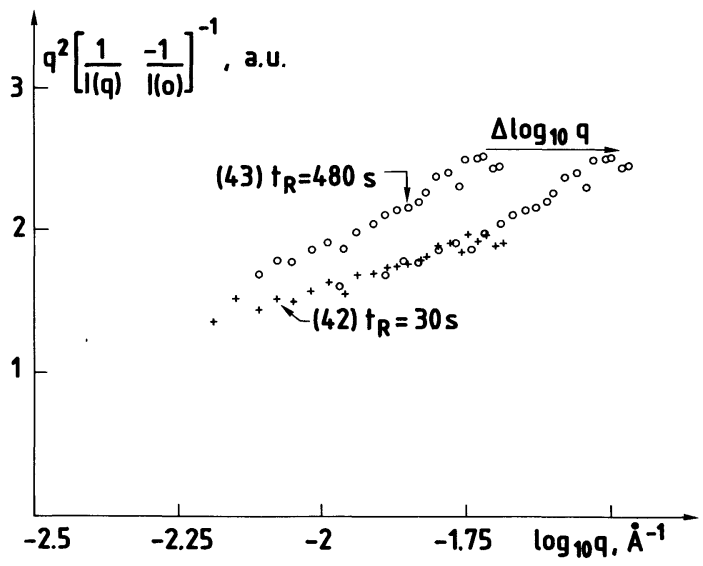

Fig. 7. - Representation of the scattered intensities of figure 4, in a reduced form $q^{2}\left(\frac{1}{I(q)}-\frac{1}{I_{0}}\right)$ as a function of $\log _{10} q$ in the intermediate $q$ range, for samples $42(+)$ and $43(0)$. The data for sample 42 are also plotted displaced horizontally along the $\log _{10} \cdot q$ axis by a constant amount $\Delta \log _{10} q$, where upon they are seen to superpose upon those for sample 43.

ing reduced times during which the stress relaxes before freezing in. Daoudi's formulation implies that there exists a reciprocal space interval in which the observed $q$ dependences

$$
q^{2}(1 / I(q)-1 / I(0))^{-1}
$$

for samples 44 and 42 coincide by rescaling the wavevector transfer of, for instance, sample 44

$$
q \rightarrow q\left(\frac{\tilde{t}_{\mathbf{R}_{42}}}{\tilde{t}_{\mathbf{R}_{44}}}\right)^{1 / 4}
$$

This corresponds to a horizontal shift of the sample 44 data if we use a logarithmic coordinate for the wavevector transfer. Figure 7 shows that the superposition is possible for samples 42 and 44 . The same holds true for data observed at $T=128^{\circ} \mathrm{C}$ and $134^{\circ} \mathrm{C}$. The superposition is however less satisfactory at lower temperatures. According to equation (10) the shift for samples 44 and 42 must be equal to

$$
\Delta \log _{10} q=1 / 4\left(\log _{10} \tilde{t}_{\mathrm{R}_{44}}-\log _{10} \tilde{t}_{\mathrm{R}_{42}}\right) \text {. }
$$

Observed shifts for pairs of samples are displayed in figure 8 , as a function of $\log _{10} \tilde{t}_{\mathrm{R}}$ for the temperatures $T=134^{\circ} \mathrm{C}, 128^{\circ} \mathrm{C}$ and $122^{\circ} \mathrm{C}$. An arbitrary origin is used on the $\Delta \log _{10} q$ scale. The reduced data for $T=134^{\circ} \mathrm{C}$ and $128^{\circ} \mathrm{C}$ are seen to fit two distinct straight lines of slope $1 / 4$. This is however not the case for the data at $T=122^{\circ} \mathrm{C}$. Here the different times $\tilde{t}_{\mathrm{R}}$ are nearer to the Rouse time than to the disengagement time $\tau_{\mathrm{dis}}$, and we expect the Daoudi superposition to fail in such a case. A more severe limitation to the application of Daoudi's superposition principle comes from the observation that the data at $128^{\circ} \mathrm{C}$ and $134^{\circ} \mathrm{C}$ with reduced time $\tilde{t}_{\mathrm{R}}$, fail to superpose. 


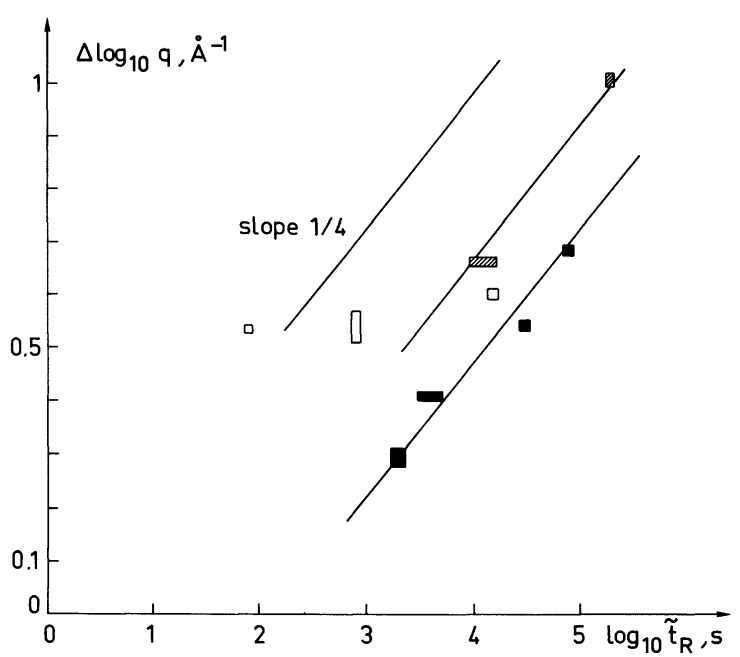

Fig. 8. - Representation of measured shifts $\Delta \log _{10} q$ versus reduced relaxation times :

- $134^{\circ} \mathrm{C} ; \square 128^{\circ} \mathrm{C} ; \square 122^{\circ} \mathrm{C}$.

The slope predicted by Daoudi at large relaxation times, is $1 / 4$.

6. Conclusion. - Using the neutron scattering technique, we have explored a large domain of reciprocal space for the observation of the pair correlations in relaxing strained polystyrene melt.

The strong temperature dependence of the rheology of polystyrene melt near the glass temperature $T_{\mathrm{g}}$ allowed us to investigate the relaxation dynamics of coils by observing their successive static form factors. By quenching the sample below $T_{\mathrm{g}}$ in a given relaxation state, it was possible to measure the static form factor in that state. The time-temperature superposition allowed us to explore several orders of magnitude of relaxation times, by choosing different oven temperatures.

Molecular theories of the rheology and in particular the reptation model could be compared in a large domain of reciprocal space. The uncertainty about the value of characteristic molecular times for our samples is a major difficulty in the interpretation of the data.

The experimental facts can be summarized as follows :

- immediately after stretching the sample, both the radius of gyration and the iso-intensity curves show affine deformation. This agrees with the idea that the entire polymer configurations are initially deformed affinely, up to a persistence length scale. It can be interpreted as indicating that the experiment does not fail to capture any major coil relaxation processes.

- a test for the coil retraction hypothesis is produced by the observation of the coil radius of gyration in the direction perpendicular to uniaxial stretching. The observed monotonic increase of this quantity is in contradiction with the behaviour predicted by Doi and Edwards on the basis of an ideal tube model.
The disagreement may be due to polydispersity effects, or to the fact that the molecular weight in our sample is too low. In that case, the disengagement masks the retraction effect.

- observation of the form factor in the intermediate wavevector transfer range, at times following the step strain of the order of the terminal relaxation time reveals a time-space superposition. The reduced form factor appears to be a universal function of $q / q^{*}$ where $q^{*} \propto t^{-1 / 4}$. However this behaviour was tested only in the limited range of reciprocal space associated with our spectrometer. It did not obey our time temperature superposition. From the theoretical point of view, it would be of importance to find out whether there exists a time and space interval in which the pair correlations for polymer melts depend on a single parameter.

From the experimental point of view, much is to be gained from the observation of relaxing polymer melts with a larger number of entanglements per coil, i.e. with higher molecular weights than $M_{\mathrm{w}}=6 \times 10^{5}$.

Acknowledgments. - We first thank R. Oberthür, our local contact at the Institut Laue-Langevin, Grenoble, for his task of general support, and for scientific discussions; thanks also to Manuel Cruz for his help on the D17 spectrometer.

The deuterated polymer was prepared by Paul Rempp, at the CRM, Strasbourg, whom it is a pleasure to thank.

R. St James, from SRM CEA Saclay, lent us her chemistry laboratory and with C. Carcaillet helped us to determine the best conditions for preparing the bulk. To the same end, we have benefited from the advice of R. Fajolle, who also with J. F. Tassin helped us to use the stretching machine of ESPCI Paris. We thank L. Monnerie for kindly offering the access to this machine. We thank P. G. de Gennes for his comments on the manuscript.

Last but not least we thank $\mathrm{H}$. Benoit for his encouragement of the project.

Appendix. - Discussion of values for $\tau_{\mathrm{eq}}$ and $\tau_{\mathrm{dis}}$ obtained from data in literature. - Consideration of polydispersity will be postponed until paragraph 4 .

1) VAlues of $\tau_{\text {eq }}$, FROM FIRST RouSe TIME. - In reptation theories [1, 14], for the process occurring at around time $\tau_{\mathrm{eq}}$, the chain cannot see the tube, but can move inside it freely : thus $\tau_{\text {eq }}$ is said to be the longest relaxation time of a Rouse chain,

$$
\begin{aligned}
\tau_{\text {eq }}=\tau_{1} & =\frac{1}{6 \pi^{2}} \frac{\zeta_{0}(T)}{k T} R_{\mathrm{g} \text { iso }}^{2} \\
& =\frac{1}{6 \pi^{2}} \frac{N b^{2} \zeta_{0}(T)}{k T}
\end{aligned}
$$


where $\zeta_{0}(T)$ is the elementary friction coefficient, and $N$ the number of statistical units of length $b$.

Neither $\tau_{\text {eq }}$ nor $\tau_{1}$ has been directly measured in a polymer melt, so we will consider data from lower molecular weight and apparently unentangled samples which exhibit Rouse-like rheology. We will then use the Rouse formulae to extrapolate to values of $\tau_{1}$ for our samples. We will use indirect data: as displayed in table AI. The first five data are for the zero-shear limit viscosity, which is in the Rouse model,

$$
\begin{aligned}
\eta & =1 / 36 \frac{\mathcal{N}}{m} N \rho b^{2} \zeta_{0} \\
& =\frac{\pi^{2}}{6 N m} k T \mathcal{N} \rho \tau_{\mathrm{eq}}
\end{aligned}
$$

where $\mathcal{N}$ is the Avogadro number, and $m$ the molecular weight of the statistical unit. We have corrected

Table AI. - Evaluation of the retraction characteristic time $\tau_{\text {eq }}=\tau_{\text {Rouse }}$ from viscosity $\eta_{0}$ or friction coeffi-

\begin{tabular}{|c|c|c|c|c|c|}
\hline \multicolumn{6}{|c|}{$\tau_{\text {Rouse }}=6 / \pi^{2} \mathcal{N} k T \eta_{0}\left(M_{\mathrm{w}}\right) M_{\mathrm{w}}\left(\frac{700000}{M_{\mathrm{w}}}\right)^{2}$} \\
\hline Refs. & $M$ & $T^{\circ} \mathrm{C}$ & $\begin{array}{l}\eta_{0}(M) \\
\text { poise }\end{array}$ & $\begin{array}{c}\eta_{0}(M) \\
\text { corrected to } \\
117^{\circ} \mathrm{C}\end{array}$ & $\begin{array}{c}\tau_{\text {Rouse }} \\
\text { extrapolated } \\
M=700000 \\
\text { at } T=117^{\circ} \mathrm{C}\end{array}$ \\
\hline $\begin{array}{l}{[24]} \\
\\
{[25]} \\
{[26]} \\
{[27]} \\
{[24]}\end{array}$ & $\begin{array}{c}35700 \\
\sim M_{c} \\
37000 \\
43100 \\
49600 \\
5000 \\
M \ll M_{c}\end{array}$ & $\begin{array}{l}217 \\
141.5 \\
227 \\
114.5 \\
217\end{array}$ & $\begin{array}{l}10^{2.12} \\
3.7 \times 10^{5} \\
10^{2} \\
10^{8.68} \\
10^{0.79}\end{array}$ & $\begin{array}{l}1.74 \times 10^{8} \\
2 \times 10^{8} \\
2.24 \times 10^{8} \\
2.04 \times 10^{8} \\
8.13 \times 10^{6}\end{array}$ & $\begin{array}{l}40000 \\
\\
49000 \\
47300 \\
27800 \\
15000\end{array}$ \\
\hline \multicolumn{6}{|c|}{$\tau_{\text {Rouse }}=3.09 \times 10^{11} b^{2} \zeta_{0} N^{2}$} \\
\hline Ref. & $\begin{array}{l}\log \zeta_{0} \\
\text { at } T_{\mathrm{g}}\end{array}$ & & $\begin{array}{l}b \\
\mathrm{~m}\end{array}$ & $\begin{array}{r}\tau \text { extrapc } \\
M=7 \\
T=1\end{array}$ & $\begin{array}{l}\text { lated to } \\
0000 \\
17^{\circ} \mathrm{C}\end{array}$ \\
\hline [17] & 2.06 & $7.4 \times$ & $10^{-8}$ & 31 & \\
\hline
\end{tabular}
cient (last line) found in literature.

the original values of $\eta$ for the mass $(\eta \propto M)$ and temperature $\left(\eta \propto a_{T}\right)$, using $a_{T}$ values from Ferry. All these data lie from 2 to $4 \times 10^{4} \mathrm{~s}$. By contrast the last entry in table AI, comes from the relaxation spectra $H(\tau)$ in its region $\tau_{1 / 2}$ dependence, giving $\tau_{1} \sim 3 \times 10^{3} \mathrm{~s}$.

In summary, for a monodisperse sample $M=700000$ and $T=117^{\circ} \mathrm{C}$, we have

$$
3 \times 10^{3} \mathrm{~s} \lesssim \tau_{\text {eq }} \lesssim 4 \times 10^{4} \mathrm{~s} .
$$

2) VALUES OF $\tau_{\text {dis }}$ FROM TERMinAl RELAXATION TIME DATA. - According to theory [7], after deformation at long times, stress relaxes as

$$
\sigma(t) \propto \sum_{n \text { odd }} \frac{1}{\dot{n}^{2}} \exp \left(-\frac{n^{2} t}{\tau_{\mathrm{dis}}}\right) .
$$

We can then assume that $\tau_{\mathrm{dis}}$ is identical to $\tau_{\mathrm{m}}$ the terminal relaxation time defined by

$$
\sigma(t) \propto \mathrm{e}^{-t / \tau_{\mathrm{m}}}, \quad t \rightarrow \infty
$$

Measurement of this quantity is possible when it is detached enough from other times, i.e. for high masses. Measurements of stress relaxation at fixed length are presented by several authors [20, 23]. They give a plot of $\tau_{\mathrm{m}}$ against $M_{\mathrm{n}}$ which we use, taking $M_{\mathrm{n}}=700000$ and correcting for tempera-

\begin{tabular}{|c|c|c|c|c|}
\hline \multicolumn{5}{|c|}{$\begin{array}{c}\tau_{\mathrm{dis}}=1 / \omega_{\mathrm{m}} \\
\omega_{\mathrm{m}}=\begin{array}{c}\text { frequency at which appears the low frequency } \\
\text { peak in } G^{\prime \prime}(\omega) \text { for high molecular weights }\end{array}\end{array}$} \\
\hline Ref. & $M$ & $T^{\circ} \mathrm{C}$ & $\tau_{\mathrm{dis}} \mathrm{s}$ & $\begin{array}{c}\tau_{\mathrm{dis}} \mathrm{s} \\
M=700000 \\
T=117^{\circ} \mathrm{C}\end{array}$ \\
\hline$[25]$ & 670000 & 170 & 130 & $3.8 \times 10^{6}$ \\
\hline
\end{tabular}
ture : these data are in table AII.

Table AII. - Evaluation of the disengagement characteristic time $\tau_{\mathrm{dis}}$ as taken equal to the "terminal

\begin{tabular}{|c|c|c|c|c|}
\hline Ref. & & & \multicolumn{2}{|c|}{$\begin{array}{c}\tau_{\mathrm{m}} \mathrm{s} \\
M=700000 \\
T=117^{\circ} \mathrm{C}\end{array}$} \\
\hline [23] & \multicolumn{2}{|c|}{$\begin{array}{l}\text { Log log plot } \tau_{\mathrm{m}} \\
\text { against } M_{\mathrm{w}}\end{array}$} & \multicolumn{2}{|c|}{$(7 \pm 2) \cdot 10^{6}$} \\
\hline \multicolumn{5}{|c|}{$\begin{aligned} \tau_{\mathrm{dis}} & =\tau_{\mathrm{m}} \propto \tau_{0} M^{3} \\
& =\tau_{0} M_{\mathrm{n}} M_{\mathrm{w}} M_{\mathrm{z}}\end{aligned}$} \\
\hline Ref. & $M$ & $T^{\circ} \mathrm{C}$ & $\tau_{0}$ & $\begin{array}{c}\tau_{\mathrm{dis}} \mathrm{s} \\
M=700000 \\
T=117^{\circ} \mathrm{C}\end{array}$ \\
\hline [20] & $\begin{array}{l}160000 \\
310000\end{array}$ & 115 & $\begin{array}{r}4 \times 10^{-12} \\
10^{-11}\end{array}$ & $\begin{array}{l}6 \times 10^{5} \\
2 \times 10^{6}\end{array}$ \\
\hline
\end{tabular}
time ", from literature data.

terminal relaxation time in stress relaxation measurement $\tau_{\mathrm{m}}$

Another measurement of $\tau_{\mathrm{m}}$ comes from the loss modulus $G^{\prime \prime}(\omega)$ : for high molecular weights, a "second" peak appears, in the low frequency range, at the frequency which is assumed to be exactly the inverse terminal time. The value obtained (Table AII) 
is close to that from the stress relaxation data. That leads finally to :

$$
10^{6} \mathrm{~s}<\tau_{\mathrm{m}}<10^{7} \mathrm{~s} \text { for } M_{\mathrm{n}}=700000 .
$$

3) VALues FOR $\tau_{\text {eq }} / \tau_{\text {dis }}$ RATIO. - A value of this ratio can be extracted from the theory $[14,22]$ which gives

$$
\tau_{\mathrm{dis}}=1 / \pi^{2} \frac{\zeta_{0}}{k T} L^{2}
$$

with

$$
\begin{aligned}
L a & =6 R_{\mathrm{g} \text { iso }}^{2} \\
a^{2} & =N_{\mathrm{e}} b^{2}
\end{aligned}
$$

where $L$ is the arc length of the tube and $N_{\mathrm{e}}$ the number of units between two entanglements. Following Ferry, $N_{\mathrm{e}}$ can be defined from the plateau modulus $G_{\mathrm{eN}}^{0}$, obtained precisely by integration of the loss modulus $G^{\prime \prime}(\omega)$ around its second peak for high masses. One obtains $M_{\mathrm{e}} \sim 18000$, a much quoted value which is also consistent with $M_{\mathrm{c}}$ from viscosity/molecular weights plots through the Bueche relation

$$
M_{\mathrm{e}} \sim M_{\mathrm{c}} / 2 .
$$

Using equations (A.1a) and (A.5), we have the estimate

$$
\tau_{\text {eq }} / \tau_{\text {dis }}=\frac{N_{\mathrm{e}}}{6 N} \simeq \frac{1}{180}
$$

which is to be compared with the ratio value obtained from literature data for $\tau_{\text {eq }}$ (A.3) and $\tau_{\text {dis }}$ (A.4)

$$
4 \times 10^{-4}<\tau_{\text {eq }} / \tau_{\text {dis }}<4 \times 10^{-2} .
$$

The uncertainty is very great and does not permit us to conclude whether the two times $\tau_{\text {eq }}$ and $\tau_{\text {dis }}$ are well distinguishable even for a monodisperse polymer.

4) EFFECT OF POLYDISPERSITY. - We must in fact take in account the polydispersity of our hydrogenated and deuterated polymer (Table I) which spreads the effective values of $\tau_{\text {eq }}$ and $\tau_{\text {dis }}$ for various observed phenomena, as each one involves different averages : these are displayed in table AIII.

For example the initial decay of stress occurs with

$$
\tau_{\mathrm{dis}}^{\sigma}=\tau_{0} M_{\mathrm{n}} M_{\mathrm{n}-1} M_{\mathrm{n}-2} ;
$$

we use this expression to compare our experimental $\sigma(t)$ to that of Tobolsky for a monodisperse sample, as we just observe the onset of terminal relaxation.
Table AIII. - Influence of non-monodisperse molecular weight distribution for the value, for different physical quantities, of their characteristic times, all equal to $\tau_{0} M^{3}$ for monodisperse polymer.

\begin{tabular}{|lcc|}
\hline $\begin{array}{l}\text { Corresponding time for } \\
\text { monodisperse polymer }\end{array}$ & $\tau_{\mathrm{eq}}$ & $\tau_{\mathrm{dis}}$ \\
\hline $\begin{array}{l}\text { initial decay of stress } \\
\mathrm{e}^{-t / \tau} \approx 1-t / \tau\end{array}$ & $\frac{M_{\mathrm{n}}}{\left\langle M^{-2}\right\rangle_{\mathrm{n}}}$ \\
\hline $\begin{array}{l}\text { rheological time } \\
(\tau=\eta / G)\end{array}$ & $\left\langle M^{2}\right\rangle_{\mathrm{w}}$ & $\left\langle M^{3}\right\rangle_{\mathrm{w}}$ \\
\hline $\begin{array}{l}\text { initial decay of } R_{\mathrm{g}} \\
\mathrm{e}^{-t / \tau} \sim 1-t / \tau\end{array}$ & $\frac{\left\langle M^{3}\right\rangle_{\mathrm{n}}}{M_{\mathrm{n}}}$ & $\left\langle M^{3}\right\rangle_{\mathrm{n}}$ \\
\hline $\begin{array}{l}\text { spread of decay of } R_{\mathrm{g}} \\
\left(\int \mathrm{d} t \mathrm{e}^{-t / \tau}\right)\end{array}$ & $\frac{\left\langle M^{6}\right\rangle_{\mathrm{n}}}{\left\langle M^{3}\right\rangle_{\mathrm{n}}}$ \\
\hline
\end{tabular}

If we now want to evaluate the time $\tau_{\text {dis }}$ for initial decay, in terminal time scale, of $R_{\mathrm{g} \perp}$, we have :

$$
\tau_{\mathrm{dis}}^{R_{\mathrm{g}}}=\tau_{0} M_{\mathrm{w}} M_{\mathrm{z}} M_{\mathrm{z}+1}
$$

for initial terminal relaxation.

The reduced time $\tau_{0}$ is the same as for stress decay, and has been drawn from Tobolsky's monodisperse sample data :

$$
\begin{aligned}
\tau_{\text {dis }}^{R_{\mathrm{g}}} & =\frac{\tau_{\text {Tobolsky }}}{M^{3}} \times M_{\mathrm{w}} M_{\mathrm{z}} M_{\mathrm{z}+1} \\
& =6 \times 10^{5} \mathrm{~s} \quad \text { (Table AII) } .
\end{aligned}
$$

We will use this value of $\tau_{\mathrm{dis}}$ to calculate the predicted curve of $R_{\mathrm{g} \perp}$ time dependence which is plotted in figure 6.

We finally recall that this time is just for the beginning of the terminal zone, afterwards it should increase and produce a spreading of the inflexion zone in $\log$ plots. The same holds for the equilibration zone, i.e. around $\tau_{\text {eq }}$

Note added in proof. - Two others samples of same blend, stretched at a ratio $\lambda=1.5$ and 2 , at $117^{\circ} \mathrm{C}$, quenched within $10 \mathrm{~s}$, give

$$
\begin{array}{ll}
R_{\mathbf{g} \perp}=200 \AA \pm 5 \quad & (\lambda=2) \\
R_{\mathbf{g} \perp}=230 \AA \pm 5 & (\lambda=1.5) .
\end{array}
$$

These are exactly the affine values.

\section{References}

[1] De Gennes, P. G., J. Chem. Phys. 55 (1971) 572.

[2] Edwards, S. F., Proc. Phys. Soc. London 9 (1967) 92.

[3] DaOudi, S., J. Physique 38 (1977) 731.

[4] Osaki, K. and KuRAta, M., Macromolecules 13 (1980) 671-676.
[5] Klein, J., Briscoes, B. J., Proc. R. Soc. London, Sect. A 53. (1979) 365

[6] De Vries, A. J., Bonnebat, C., Beautemps, J., J. Polym. Sci. Polym. Symp. 58 (1977) 109-156. 
[7] Picot, V., Duplessix, R., Decker, D., Benoît, H., Boué, F., Cotton, J. P., Daoud, M., Farnoux, B., Jannink, G., Nierlich, M., De VRIes, A. J. and Pincus, P., Macromolecules 10 (1977) 436.

[8] Bouḱ, F., Jannink, G., J. Physique Colloq. 39 (1978) C2-183.

[9] FAJOlle, R., Thèse de Docteur Ingénieur, Université Paris VI (1980).

[10] Boú, F., Nierlich, M., Leibler, L., to be published in Polymer.

[11] De Gennes, P. G., Scaling concepts in Polymer Physics, Chapter VIII (Cornell University Press, London) 1979.

[12] KLeIN, J., Macromolecules 11 (1978) 852.

[13] Daoud, M., De Gennes, P. G., J. Polym. Sci. Polym. Phys. Ed. 17 (1979) 1971

[14] Doï, M., Edwards, S. F., J. Chem. Soc. Faraday Trans. 274 (1978) 1789, 1802, 1818.

[15] Hydraulic stretching machine of PCSM Laboratory (L. Monnerie), ESPCI, built by P. Sergot and C. Pambrun.

[16] Tangara, C., Summerfield, G. C., King, J. S., Berliner, R., MILDNER, D. F. R., Macromolecules 13 (1980) 1546, 1548.
[17] Cotton, J. P., Decker, D., Benoît, H., Farnoux, B., Higgins, J., Jannink, G., Ober, R., Picot, C. and Des Cloizeaux, J., Macromolecules 7 (1974) 863.

[18] Ferry, J. D., Viscoelastic properties of polymers (Wiley, New York) 1970

[19] Ref. [17], page 314.

[20] ТовоLsKy, A. V., J. Polym. Sci., Polym. Lett. 2 (1964) 103-108.

[21] BALL, R., to be published.

[22] Graessley, W. W., J. Polym. Sci. Polym. Phys. Ed. 18 (1980) $27,34$.

[23] Akovali, J., J. Polym. Sci. A 25 (1967) 875.

[24] Fox, Gratch, LoshaeK in Eirich, F. R., Rheology (Academic Press, New York) 1956, Vol. I, p. 446, quoted [17], p. 269.

[25] Marin, G., Graessley, W., Rheol. Acta 16 (1977) 527-533.

[26] Rudd, J. F., J. Polym. Sci. 14 (1960) 459-474.

[27] PlazeK, J. D., J. Phys. Chem. 69 (1965) 10.

[28] Williams, M. L., J. Phys. Chem. 59 (1955) 95. 